\title{
Library Cooperation: The Ideal and the Reality
}

Cooperation as a form of social, professional, and organizational behavior is susceptible to analysis by a variety of conceptual constructs. In studying library cooperation as a process of exchange, it is possible to approximate its power to affect the ability of libraries to meet their professional obligations.

W hen Samuel S. Green unfurled THE BANNER of library cooperation in 1876, he was expressing two concerns: the need for a single library to provide a level of service which would satisfy its clients, and the concomitant need for a regularity in the means by which the librarian could increase the possibilities of service to a level nearer to the librarian's own expectations of what might be satisfactory service. ${ }^{1}$ I would like to look at cooperation as a social phenomenon by which libraries mutually engage to increase the service capabilities of a single library and by which librarians extend their options to serve clients, including those for whom they actually have no direct responsibility. In addition, I would like to place the phenomenon of cooperation into a conceptual framework in order to relate it to other social phenomena and, consequently, the better to analyze it as it ap-

Michael M. Reynolds is professor, College of Library and Information Services, University of Maryland. This paper is based on a presentation made at the ACRL University Libraries Section institute on "The University Library's Role in Information Networks," Las Vegas, Nevada, June 1973. Proceedings of this institute are scheduled for publication in fall 1974. plies specifically to library cooperation. Finally, I would like to point out the limitations in the use of library cooperation as a means by which a library can expand services or through which it can achieve economies in its operation.

The Idea of Cooperation AND ITS IMPORTANCE TO LIBRARIANSHIP

Central to a profession is a "collectivity or service" orientation which is unique to that profession and which its practitioners accept as contributing to a purpose essential to society and to man. ${ }^{2}$ The formalization of this purpose or function, in the case of the profession of librarianship, is to preserve the record of man's accomplishmentseven perhaps to make it available and to assist in increasing man's body of knowledge. The purpose has been expressed institutionally in the concept of the library, by means of which a set of complex behaviors are organized so as to carry out its social function; formalized instrumentally in the library as an organization; and actualized in the role of the librarian.

While the library may express in its priorities the imperatives of a particular historical period and emphasize one of its major functions-preservation, ac- 
quisition, or dissemination-and, consequently, may require varying interests and skills from librarians, the constants for all libraries are three: recorded discourse, a current or potential client, and an intermediary who is responsible for facilitating the client's use of the record-the librarian. While institutions, e.g., libraries, are often transformed to achieve greater compatability with changes in the character and the social urgencies of the society in which they are embedded, nevertheless as institutions they continue to provide society with relative certainty about the nature of their purpose. In addition to a client, a profession also requires an exclusive body of knowledge (or the possession of the skills necessary to utilize a specialized technology) and an ethic (or a learned set of social rules). It is this ethic which provides clients and colleagues with the expectation that the professional will perform in a positive manner those activities which are institutionally relevant at that particular time. This ethic represents a norm of professional behavior, and actions which are outside this norm are likely to produce negative consequences in the client relationship.

The professional ethic is not only expressed in the manner in which librarians carry out those tasks necessary to fulfilling the major functions of the library, but since the practitioner places a high value on such ideas as the need for the library, the purpose of the library, and the contribution that its functions make to society, these ideas are also intrinsic to the professional ethic. In fact, one can expect that the power of the professional to influence the total of the profession will increase as the level of abstraction of the profession's value to society or the nature of its contribution increases. There is, for example, more power in the abstract idea that libraries should provide ser- vices which will be of the most value to their clients than there is in the service objective of increasing the annual circulation by 2 percent or 150 books in a particular rural library. On the other hand, as the degree of abstraction increases, the profession's ability to achieve absolute success decreases. Instead it must accept relative failure for, even setting natural biological and physical constraints aside, the profession represents only an aspect of a larger social system consisting of a multitude of differentiated behavioral and organizational subsystems. The social worker cannot at any one point place each individual within a society in that society's mainstream of normalcy; the physician cannot anticipate or cure each person's illness or postpone indefinitely his death; the librarian cannot have available and effectively organized for immediate access that body of literature or of information that will best meet the articulated and unarticulated current and future needs of a diverse clientele or even the various needs of a single client. ${ }^{3}$ Yet, in our time, the professional ethic suggests to the librarian that he attempt to do just this-give the absolute in service-and the client has come to expect that the librarian ought to succeed in his attempt.

In the sense that success cannot be achieved absolutely, much that is implied in library cooperation has only a symbolic value. This is true even though there are significant activities which are associated with cooperation and which may be seen as capable of satisfying a demand and furthering an interest that an individual library or group of libraries could not separately meet under prevailing conditions. In his role as an active intermediary between recorded discourse and the client, the librarian finds in the professional ethic the basis for developing, as in the case of library cooperation, organizational responses 
which may result in making additional resources available.

However, for the librarian to be committed to increasing client satisfaction is not in itself sufficient to produce success since success would require, at minimum, the utilization of the resources of other libraries over which he does not have direct control. Nonetheless, it may be just as well for the profession to believe that if outside resources were made available, the client could, at least, be served in his need for material, and for the client to believe that, in fact, he has access to library resources beyond the immediate library serving him and that he can be satisfied in this way. To the extent that this notion-that libraries share in the responsibility of satisfying all clients of libraries-is pervasive and accepted by the profession and is supported by the particular environment to which the library is responsible, it will be a determinant in the amount of mutually beneficial interaction that will take place. ${ }^{4}$ Yet because there is a need, it does not follow that a group of libraries with the same need will agree upon and develop the means to accommodate to their separate but mutual need or that the need will generate any particular action. Nor does it follow that all those participants who are mutually engaged in satisfying their individual needs through a collective will have a common interest in returning to the collective an amount proportional to what they receive.

\section{COOPERATION APART FroM LIBRARY COOPERATION}

The idea of cooperation has, in itself, an extremely low specificity. Although cooperation is not a goal in itself, whenever it is presented as a goal a change in a social state is nonetheless always implied. Cooperation is both a process and a means through which two or more separate entities accommodate to each other to approach a mutually satisfactory condition. As a process it is an ongoing activity involving interactions; as a means it is intended to produce an outcome or product. Further, cooperation is a voluntary association in which each of the participants retains the right to determine the extent of its own accommodation, the appropriateness of the accommodation of those others involved, and the option to dissociate from the collective without direct penalty. Coordination is also a process and a means by which participants are associated. Here, however, a directing mechanism is explicit as are the possibilities that penalties or sanctions for non-compliance or dissociation can be invoked. When cooperation is so defined as to be a process/means involving a dynamic set of interrelationships, it can then be variously studied as to its significance as a means toward achieving discrete ends or purposes, in terms of its efficiency and/or effectiveness in achieving those ends or purposes, or as systems of behavior.

Different analytical or conceptual constructs-call them paradigms or propositions or strategies-for explaining cooperation have been developed to explain its nature, to understand the forces which generate it, to characterize the behaviors of the participants, and to anticipate the outcomes and consequences. For example, one can explain cooperation intuitively and declare that since the natural state of man is to live together in harmony, cooperation is the expression of the means by which this is done; one can hold that disharmony is the natural state of man and since men must, of necessity, live in proximity to each other and depend on each other to survive, cooperation is the means by which conflict is mitigated and life is sustained; one can hypothesize that cooperation is, in actuality, compliance or the means by which a greater 
and a lesser magnitude of power coexist; ${ }^{5}$ or one can show that cooperation as an interaction is a form of exchange of goods, be these goods either material or nonmaterial. ${ }^{6}$

For the purpose of examining cooperation among libraries, there are considerable advantages in regarding cooperation as a form of exchange which not only can be expressed in real or financial terms but also can have a social/ psychological dimension which includes such intangibles as prestige, respect, and friendship. It therefore follows that individuals or groups would not engage in any cooperative activity resulting in a negative outcome for them, in terms of such things as goods, energy, freedom, or self, unless a commensurate or greater quantity were received in return.

In further analyzing cooperation as a process of exchange, one can discern differences in the exchanges of goods and of services, as well as variables in behavior among the total of the participants and between discrete sets of participants, which in turn are predicated upon the variations in reciprocity. For example, the large public university libraries generally accommodate libraries of the same size and kind and those smaller borrowing libraries for which they have an overt obligation, i.e., those located in the same state, since they are reciprocated in kind or in social-professional benefits. If the cost goes beyond what is essentially an equal exchange, it can be expected that stress will be introduced into the relationship, as when the volume of requests from these borrowing libraries progressively increases, or if the requests for materials are not adequately identified or they represent a run on one topic. At that point it can be anticipated that the supplier library will adapt in such a way as to modify the relationship-usually by introducing inhibitory conditions-and thereby provide for a return to reciprocity. Though it would be possible to develop a classification of orders of exchange, involving obligations, rights, and duties, ${ }^{7}$ one can generally assume that "in small groups with common interests there is a surprising incidence of the exploitation of the great by the small"; ${ }^{8}$ but it also follows that the borrower libraries must and will observe the mores and conditions that supplier libraries impose in order that they may maintain what they perceive to be an appropriate level of accommodation. The idea of reciprocity is integral to the idea of exchange and social equilibrium, ${ }^{9}$ and social cohesion may be dependent to a considerable degree on "the reciprocity of service and return service. . . ."10 In its purest form, cooperation would be a voluntary form of association in which each participant would contribute an equal amount, and in exchange for this contribution a consequence or an event would result from which each would derive an equal benefit.

At this point, I would like to establish another convention about library cooperation. Though it necessitates a personto-person interaction, library cooperation actually takes place only within the context of formal organizations, since individuals do not themselves own either the resources or, since they contract to exchange them for wages, those services involved in the exchanges. In summary then, library cooperation may be defined as a voluntary exchange of goods and services between individuals employed in formal organizations.

\section{The Reality of LibraRy COOPERATION}

Librarians are not libraries, nor is the library merely the sum of its buildings, materials, and staff; rather, it represents a social concern with preserving and accessing recorded discourse. On the other hand the library, with its buildings, materials, and staff, is an organization. To 
a certain extent Esterquest articulated the organizational difficulties associated with library cooperation. ${ }^{11}$ These, however, are more than difficulties which can be transcended through good-will or careful planning and may instead represent inherent limitations in the ability of libraries to affect the success of their programs through cooperation.

A library is not like a private corporation nor even one of the separate units in a conglomerate. Instead it represents a special type of organization in that it is not self-supporting or self-directing. Each library derives its goals and its performance objectives from the orientation of the larger organization of which it is a part, whether the larger organization is a governmental or educational body, a municipality, or a business firm. At the most fundamental level, those resources the library obtains from the larger organization are given with the expectation that the library will utilize them to produce goods and services that will further the well-being of that larger unit. Libraries are independent only from each other and can be interdependent only to the extent that it is to the advantage of the larger units-or not to their disadvantage-to act in a mutually beneficial manner. Interlibrary loan, for example, is not only an alternative for the library; it is also an efficient alternative for the larger unit, permitting it to meet at a lower cost those obligations required of the library. Not only does interlibrary loan obviate the need to acquire particular items, it also has the potential of reducing the obligation of the larger unit to have immediately available in the library large stocks of materials in anticipation of future need.

To some degree libraries have had the autonomy to engage in certain kinds of cooperation, especially those which are of an "in-house" character involving library technology such as cataloging or classification. This may represent pri- marily a lack of concern on the part of the superior organizational unit for the technical internal operation of a subordinate; however, cooperation in such areas does offer the library a real means of reducing the relative cost of its support by the larger organization.

A librarian will most likely fail the larger unit if he does not participate in these extended relationships as modes of economizing and limiting costs, just as he may fail the larger unit if he provides goods and services to other libraries or to the clients of other libraries that are not reciprocated demonstrably for his own clients. In the first instance, self-help through interorganizational exchange is understood as essential to the idea of achieving purpose; the second instance may be regarded as an inability to discriminate among priorities and may well represent professional malpractice against the funding agency, which in turn can justifiably question the legitimacy of a professional claim upon its resources. Attempts by libraries to cooperate beyond "in-house" arrangements or the occasional interlibrary loan become progressively more difficult. First, such attempts involve greater complexity, as in specialized acquisitions programs or in sharing stored resources, and impact upon the library's primary client group and the library's primary organization in a more tangible way in terms of the availability of resources, the proprietorship of the materials, and even the domain of the larger unit. Second, the costs of additional units of the collective good must be shared in proportion to the additional benefits, ${ }^{12}$ and there are no concrete formulations by which equity can be maintained in these exchanges without the use of currency. Third, librarians are not prepared to act as brokers between the agency, the library organization, and the collective. Fourth, and possibly most important, the larger organization, which is performing in an en- 
trepreneurial mode and is subject to political, economic, and legal constraints itself, does not provide an ambience for furthering interorganizational cooperation among such subordinate units as libraries.

These limitations, if tacit, are nevertheless real and are generally accepted by librarians as they discuss and negotiate with each other..$^{13}$ It may also be socially imprudent for librarians, their clients, and the administrators of the larger units to analyze and discuss the inhibitory consequences of this organizational relationship, since it is to the benefit of all concerned, especially the profession, both to maintain the image of a forward thrust and to identify with cooperation, reflecting as it does a rationalization in a society which places a high value on orderliness and efficiency. In this sense much in library cooperation as a means has only a symbolic purpose. In a study of cooperation among community health organizations, Levine and White perceive this complex of separate agencies as a health system. ${ }^{14}$ In a similar manner a complex of libraries, also not formally related, can be viewed as a library material and information service system. An image of libraries as agencies of organizations which are seeking advantages for their particular client groups-the organizations within which they exist-can produce different insights and findings than if the libraries are perceived as coalitions of autonomous professional organizations engaging in broadly based interorganizational cooperation devoted to the greater social good. In the former, success would be a function of how effectively a library met the requirements for library services of the larger organization; as a coalition of professional organizations, the question would be how well they met society's archival requirements and its need for materials and information.

Causing further discrepancy between the ethic and its actualization through cooperation is the lack of rigid controls over the professional library staff. Insofar as each individual librarian approximately conforms to the group's expectations, especially in performing professionally desirable work, probably neither the library organization, the library administrator, nor the client will attempt to make precise judgment on the quality of the unit of work. This acceptance may be especially significant when it involves the work of those engaged in cooperative library activities, which tend to be outside the rationalized tasks and procedures by which the library typically generates its products. As Knight demonstrated, professional efforts not in this mainstream of work, interlibrary loan for example, tend to take on the character of individualized negotiations outside the formal library structures. ${ }^{15}$ Here the controls over the interaction, whether with a client or with another library, are inexact and every decision or action, be it appropriate or inappropriate for the client, can be justified by the staff member if he claims that the action was necessary to maintain the primacy of the organization. For underlying the professional basis for the librarian's efforts in acting cooperatively is the sense that, regardless of the professional identification, approbation for the practitioner ultimately rests within the library organization with which he is associated. In fact, since neither the professional nor the organizational objectives of library cooperation have been clearly stated, and consequently the criteria for evaluative measurement cannot be derived, it may well be that a judgment of failure or success in a transaction is no more than an intellectual exercise or a function of personality.

A major advantage in viewing cooperation as exchange is that it may lead to more rational explanations of individual and group behavior and, hopefully, 
result in realistic expectations. Too frequently, theorists and planners do not simulate the social environment or truly represent the participants engaged in an exchange. It is as if they assume a frictionless society of non-people who have arrived at an identical system of values, ${ }^{16}$ and that all similar groups of these non-people have defined the same roles for themselves and that each, in turn, is familiar with the diversity of roles and fully accepts the self-definition of role which each has developed.

What exists is actually far from this. In exchange each participant will tend to seek an accommodation that will be advantageous to himself; and there probably will be as many value constructs, role definitions, and interpretations of how these roles are expressed in tasks as there are individuals involved. Consequently, distinctions must be made between decisions in policies for cooperative efforts and the implementation of these decisions, just as one must differentiate between the professional abstractions with which librarians identify and the organizational environment which determines what might actually take place after the choice is made.

When a service need is frustrated or the library organization is under great pressure, it can be expected that librarians will have unrealistic expectations and attach exaggerated hopes to a proposed solution or a program, regardless of how nebulous-as in cooperationthe solution or the program may be. Interlibrary loan may be such an example, as are the union list and catalog, the bibliographic center, ${ }^{17}$ and the centralized card production facility.

If librarians as professionals within organizations are not able to achieve the unrealistic service objectives that they may impose upon themselves or which are imposed on them from the orientation of the larger organization, it is not likely that they will do so when joined with other librarians in a self-help association.

Patently, it would not be possible for weak libraries to become strong libraries unless strong libraries were prepared and permitted to carry a disproportionate share of the cost of the exchange. A library limited by its resources cannot meet unqualified client expectations. Since their power to effect fundamental change through cooperation is limited, librarians would be better advised to explore functional and structural alternatives, perhaps within coordinated systems; or they should seek associations with those organizations which perform the functions previously assumed by the individual library and which for a fee provide these as services to the library. It is questionable whether librarians are merely performing a professional or organizational disservice by fostering false hope and projecting and perpetuating the illusion to their clients that through the metaphysical or sentimental wonder of cooperation they can nullify the consequences of fundamental deficiencies and constraints, or whether as professionals they are attempting to improve the status of their calling by raising or inducing upward the level of the client's expectation for service.

\section{ConCLusion}

As policy makers and practitioners, librarians should, of necessity, explore those alternatives which reduce client dissatisfaction and organizational tension. Among the alternatives is library cooperation, which is not only an expression of the professional ethic but is a valid mechanism for broadening the base of library services. They should attempt to define and calculate the advantages and limitations of cooperation as the only means of meeting service obligations, being sensitive to the library's existence as a part of a larger 
social/professional system as well as the total of the organizational and personal factors implicit in cooperation as a process/means.

In this paper I have explored some of those factors which are fundamental to an understanding of cooperation among libraries as a means of attaining unarticulated professional goals as well as organizational objectives. Library cooperation can be defined as a voluntary exchange of goods and services between individuals employed in formal organizations, by means of which the potential for service might be increased. I have suggested a conceptual construct for the analysis of this exchange within the organizational context in which the library performs. By using this concept of cooperation as exchange I have indicated that the environment in which the library operates may narrow the number of organizational alternatives available to it through cooperation. No less critical to the power of cooperation in achieving a satisfactory level of professional and organizational service is the normative behavior of the librarian, within his institutionalized and organizational role.

Efforts to promote cooperation should continue because of the social value for libraries, regardless of the operant facts, since the consequences of the idea of cooperation not being present will be detrimental to the library as an institution and as an organization, and will inhibit the possibilities for developing other alternatives to achieve professionally desirable goals-goals which frequently do not lend themselves easily to operational definitions.

\section{REFERENCES}

1. Samuel S. Green, "The Lending of Books to One Another by Libraries," Library Journal 1:15 (Sept. 1876).

2. William J. Goode, "Encroachment, Charlatanism, and the Emerging Profession; Psychology, Sociology, and Medicine," American Sociological Review 25:902-14 (1960), p.903.

3. Philip H. Ennis, "The Study of Use and the Users of Recorded Knowledge," Library Quarterly 34:305-14 (Oct. 1964).

4. Michael M. Reynolds, ed., Reader in $\mathrm{Li}$ brary Cooperation (Washington: Microcard Editions, 1973), p.3.

5. Amitai Etzioni, A Comparative Analysis of Complex Organizations; On Power Involvement and Their Correlates (New York: Free Pr., 1961).

6. See, respectively, George Homans, "Social Behavior as Exchange," American Journal of Sociology 63:597-606 (May 1958); and Mancur Olson, Jr., The Logic of Collective Action; Public Goods and the Theory of Groups (Cambridge, Mass.: Harvard Univ. Pr., 1965).

7. Alvin W. Gouldner, "The Norm of Reciprocity: A Preliminary Statement," American Sociological Review 25:161-78 (April 1960).

8. Olson, Logic of Collective Action, p.35.

9. Gouldner, "Norm of Reciprocity," p.168.

10. Georg Simmel, The Sociology of Georg
Simmel (Glencoe, Ill.: Free Pr., 1950), p.387.

11. Ralph T. Esterquest, "Co-operative Control of Library Resources; The Realities of Cooperation," Medical Library Association Bulletin 47:369-74 (Oct. 1959).

12. Olson, Logic of Collective Action, p.27.

13. R. D. Laing, "Rules and Metarules," in his The Politics of the Family and Other Essays (New York: Pantheon, 1969), p.10316.

14. Sol Levine and Paul E. White, "Exchange as a Conceptual Framework for the Study of Interorganizational Relationships," Administrative Science Quarterly 5:583-601 (1961).

15. Kenneth E. Knight, "Ill-Structured Problem Solving in a Natural Situation: A Model of the Decision Behavior of a Librarian," in C. Edward Weber and Gerald A. Peters, eds., Management Actions: Models of Administrative Decisions (Scranton, Pa.: International Textbook Co., 1969), p.246-68.

16. Robert Boguslaw, The New Utopians, A Study of System Design and Social Change (Englewood, N.J.: Prentice-Hall, 1965).

17. See, respectively, Robert B. Downs, ed., Union Catalogs in the United States (Chicago: American Library Assn., 1942); and Michael M. Reynolds, "Interlibrary Loan: A Reference Service," Library Trends 12: 425-36 (Jan. 1964). 